\title{
FITOTOXICIDADE DE HERBICIDAS PRÉ EMERGENTES EM MUDAS CLONAIS DE EUCALIPTO
}

\author{
Ivan da Costa Ilhéu Fontan ${ }^{1}$ \\ Marlon Michel Antônio Moreira Neto ${ }^{2}$ \\ Sharlles Christian Moreira Dias ${ }^{3}$
}

Resumo: O objetivo deste estudo foi avaliar a fitotoxicidade de herbicidas pré emergentes sobre mudas de Eucalyptus urophylla, de modo a subsidiar recomendações de uso em condições de campo. O trabalho foi conduzido em viveiro de eucalipto localizado em Curvelo/MG, utilizando-se os herbicidas pré emergentes isoxaflutole, flumioxazin, sulfentrazone e clomazone + carfentrazone-ethyl, simulando uma taxa de 200 l/ha de calda. O experimento foi estabelecido em um delineamento inteiramente casualizado, com 15 repetições. A sensibilidade dos clones foi avaliada por meio da incidência e da severidade dos sintomas de intoxicação foliar nas mudas, verificadas um, cinco e dez dias após a aplicação. Os herbicidas isoxaflutole e flumioxazin não provocaram reações adversas às mudas, permitindo sua utilização sobre as plantas. Já a pulverização de sulfentrazone e clomazone + carfentrazone-ethyl provocou a manifestação de sintomas de fitotoxicidade (manchas foliares e murcha apical), e desta forma, sua aplicação não é recomendada sobre as mudas, e seu uso deve ser limitado entre as atividades de preparo de solo e plantio.

Palavras-chave: Eucalipto; Fitotoxicidade; Herbicida.

\footnotetext{
1 Instituto Federal do Espírito Santo - Campus Ibatiba, Brasil. E-mail: ivanfontan.florestal@gmail.com.

2 Plantar - P\&D, Brasil. E-mail: marlon-moreira@hotmail.com.

3 Plantar - P\&D, Brasil. E-mail: sharlles.dias@gmail.com.
} 